\title{
Confirmatory Factor Analysis of Work Attributes of Pharmaceutical Sales Representatives during COVID-19 in Nigeria
}

\section{Theophilus Ehidiamen Oamen ${ }^{1}$ and Lawal Banjo Moshood (Ph.D.) ${ }^{2}$}

${ }^{1}$ Department of Clinical Pharmacy and Pharmacy Administration, Faculty of Pharmacy, Obafemi Awolowo University, Ife, Osun State, Nigeria.

Email: oamentheo@yahoo.com; +2348183055245,+2348033733547

Orchid no: 0000-0002-5114-064X

${ }^{2}$ Department of Social Sciences Education, Faculty of Education, University of Ilorin, Ilorin, Nigeria. Email: lawal_banjo@yahoo.com

Cite this article:

Oamen T.E., Moshood L.B. (2021), Confirmatory Factor Analysis of Work Attributes of Pharmaceutical Sales Representatives during COVID-19 in Nigeria. British Journal of Management and Marketing Studies 4(4), 1-8. DOI: 10.52589/BJMMSX3SAWP6I.

\section{Manuscript History}

Received: 13 Sept 2021

Accepted: 30 Sept 2021

Published: 8 Oct 2021

Copyright $\odot 2020$ The Author(s). This is an Open Access article distributed under the terms of Creative Commons Attribution-NonCommercialNoDerivatives 4.0 International (CC BY-NC-ND 4.0), which permits anyone to share, use, reproduce and redistribute in any medium, provided the original author and source are credited.
ABSTRACT: The purpose of this study was to investigate the validity of exploratory factor analysis (EFA) study on the work attributes of pharmaceutical sales executives in Nigeria using confirmatory factor analysis (CFA), and furthermore to evaluate the relative importance of the work attributes. An analytical study design used a 13-item, 5point Likert scale questionnaire administered to 226 pharmaceutical sales executives using a simple random sampling method. Data analysis using the Statistical Package for Social Sciences (SPSS) and Analysis of Moment Structures (AMOS) with a significance level set at $p<0.05$. The measurement model was evaluated using the maximum likelihood method. Model fit criteria measures for CFA were satisfactory $(C M I N / d f=2.297 ; N F I=0.917 ; \quad T L I=0.905 ; C F I=0.950$; RMSEA=0.064). The study showed that the most dominant attribute was involvement in community education programs with a regression coefficient of 0.892, and the least was limited access to customers (0.446). Convergent validity measures were acceptable. Divergent validity can be enhanced by including more items. The study confirmed the validity of the EFA study outcomes obtained from the previous research work.

KEYWORDS: Confirmatory Factor Analysis, Exploratory Factor Analysis, COVID-19, Pharmaceutical Sales Executives, Convergent Validity, Divergent Validity, Model Fit. 


\section{INTRODUCTION}

Confirmatory factor analysis (CFA) belongs to a group of analytical tools used in structural equation modeling (SEM) to confirm the theoretical basis of a proposed model [Henson \& Roberts, 2006; Fan et al., 2016]. CFA is usually applied to investigate the validity of latent variables or constructs developed from an exploratory factor analysis (EFA) [Schreiber, 2020; Matsunaga, 2020; Levine, 2005; Kline, 2005; Thompson, 2004]. As a statistical tool CFA is used to establish or confirm measurement properties of instruments of data collection. This is with the notion that an instrument, be it adopted or adapted, may be well validated in other cultural groups but not in another sample (culture specific). CFA therefore confirms the construct validity of the instrument(s) in relation to the researchers' culture because if the instrument is not measuring something meaningful, the consequent analyses may be meaningless or even misleading [Cheung, 2009]. Previous studies have examined the various work roles and responsibilities of pharmaceutical sales executives to include drug information services to health care, medication supply to retailers, customer care services, community enlightenment, and direct selling [Ugbam \& Okoro, 2017; Oamen, 2021a; Oamen, 2021b]. However, to the best of the researchers' knowledge, there has not been a study that specifically confirmed the work attributes of pharmaceutical sales representatives during COVID-19 especially in Nigeria.

Work attributes are the traits that naturally make a person unique and can determine his/her effectiveness in a certain job role. Due to the global challenge presented by the COVID-19, the work attributes and occupational structures have largely adapted to accommodate the adverse effects of the COVID-19 on the work-life characteristics of sales professionals in the pharmaceutical industry. Several studies have shown that there have been effects on both work life and the characteristics of job roles [Elbeddini \& Yeats, 2020; Bashir et al., 2021; Oamen, 2021a; Oamen, 2021b]. Hence, there is a need to investigate the explored factors in a previous study by Oamen [Oamen, 2021c] to confirm the validity of the structural model using CFA. Therefore, the purpose of this study was to validate the 13-item questionnaire on the work attributes of pharmaceutical sales executives involved in pharmaceutical marketing in Nigeria. The initial EFA study produced an 11-item pattern matrix composed of 3 factors namely: F1 (sales-related), F2 (communication/access-related), and F3 (COVID-related activities) [Oamen, 2021c]. Therefore, a CFA is required to validate the proposed model of the exploratory study.

\section{METHODOLOGY}

The sample size used for the initial published study was 170 while this study used a larger population of 226 respondents. The target sample was obtained using a random sampling method. The questionnaire items were rated on a Likert scale of 1 to 5 , where 1 is the least relevant and 5 is the most relevant work attribute during the COVID-19 lockdown period in Nigeria. The study used CFA as a tool to develop a structural model from the initial 13-item factor structure obtained from the previously done EFA [Goretzko et al., 2019]. The maximum likelihood method option was selected to compute CFA. The preferred method of factor extraction for EFA was principal axis factoring with the promax rotation method-a type of oblique extraction technique [Matsunaga, 2010; Henson \& Roberts, 2006]. This analytical approach was based on the assumption that the items or indicators are related, 
compared to using typical orthogonal-rotation methods like principal component analysis with the varimax rotation method [Matsunaga, 2020]. The resultant factor structure obtained was examined using eyeballing techniques to identify items with factor loadings less than 0.45 or cross-loadings of more than 0.2 difference in absolute value [Henson \& Roberts, 2006; Thompson, 2004]. However, two items: 'improved access to customers' and 'made fresh business contacts/opportunities' have factor loadings below the threshold of 0.45 and were removed from the analysis, and the process was re-run to achieve a final pattern matrix structure consisting of three factors or latent variables (F1, F2, and F3) with 4, 3, and 2 items/indicators respectively. Appropriate measurement options were configured in the output/plugin platforms in SPSS AMOS to generate model fit indices, model validity indices, and standardized regression estimates of variables required for inferential analysis.

\section{RESULTS AND DISCUSSION}

The impact of the COVID-19 on operations and work attributes has been significant. Hence, the focus of this study was to confirm using CFA the previously proposed model of work attributes as reported in a published EFA study [Oamen, 2021a]. The objective of the study was to perform a CFA of work attributes of pharmaceuticals sales executives in order to provide possible validation of a previous EFA study.

Table 1: Pattern Matrix Structure from Initial Exploratory Factor Analysis

\begin{tabular}{|c|c|c|c|c|}
\hline \multirow[b]{2}{*}{$\begin{array}{l}\text { Item } \\
\text { Code }\end{array}$} & \multirow[t]{2}{*}{ Work Attributes } & \multicolumn{3}{|c|}{ Factor $(\mathbf{F})$} \\
\hline & & 1 & 2 & 3 \\
\hline WL & Increased workload & 0.822 & & \\
\hline RR & $\begin{array}{l}\text { Recognition/commendation for sales efforts during the } \\
\text { pandemic }\end{array}$ & 0.784 & & \\
\hline $1 \mathrm{P}$ & Drug information provider & 0.624 & & \\
\hline SP & Increased sales of your products & 0.554 & & \\
\hline $\mathrm{HCP}$ & Limited access to doctors, nurses, and pharmacists & & 0.874 & \\
\hline $\mathrm{CS}$ & Limited access to your customers & & 0.621 & \\
\hline $\mathrm{OC}$ & $\begin{array}{l}\text { Observed compliance by people during the lockdown } \\
\text { period }\end{array}$ & & 0.501 & \\
\hline $\mathrm{VC}$ & Virtual consultation with clients/customers & & 0.480 & \\
\hline CSA & Involved in COVID-19 screening activities & & & 0.754 \\
\hline $\mathrm{CE}$ & Involved in community education & & & 0.712 \\
\hline
\end{tabular}

Table 1 shows the pattern matrix composed of 10 (ten) work attributes were obtained with factor loadings of more than 0.45 . The minimum cutoff was 0.45 for inclusion into the pattern matrix. Three key factors were obtained namely: Factor 1 with WL, RR, IP, and SP; Factor 2 with HCP, OC, OC, and VC; and Factor 3 with CSA and CE. Factor 1 represented workrelated constructs, Factor 2 represented access/communication-related constructs, and Factor 3 represented COVID-19 related constructs. 
British Journal of Management and Marketing Studies

ISSN: 2689-5072

Volume 4, Issue 4, 2021 (pp. 1-8)

www.abjournals.org

Table 2: Model Fit Measures from Confirmatory Factor Analysis

\begin{tabular}{llll}
\hline Measures & Threshold values & Results & Inference \\
\hline Model chi-square $\left(\mathrm{X}^{2}\right)$ & $\begin{array}{l}\mathrm{p} \text {-value }<0.05(\text { sensitive } \\
\text { to sample }>200)\end{array}$ & 0.01 & supported \\
Tucker Lewis Index $(\mathrm{TLI})$ & $\mathrm{TLI}>0.90, \mathrm{NFI}>0.90$ & $\mathrm{TLI}=0.905$, & supported \\
$\begin{array}{l}\text { Normed-Fit Index } \\
\text { Comparative Fit Index }(\mathrm{CFI})\end{array}$ & $\mathrm{CFI}>0.90$ & $\mathrm{CFI}=0.917$ & supported \\
Root-mean-square-error-of- & RMSEA $<0.08$ & 0.064 & supported \\
approximation (RMSEA) & & $\mathrm{X} 2=55.118, \mathrm{df}=24$ & supported \\
CMIN/DF & Less than 5 & $(=2.297)$ & \\
\hline
\end{tabular}

In Table 2, the output of CFA was obtained from the pattern matrix by using the AMOS packager. The model fit measures were compared against threshold values for determining model fit [Kline, 2005]. All key parameters were found to be within the acceptable range for a good measurement model. This invariably affirms the theoretical model presented by the EFA study [Oamen, 2021a] and thus validates the outcomes.

Table 3: Measures of Reliability (Cronbach Alpha Test)

\begin{tabular}{lcccll}
\hline Attributes & Factor (F) & No. of items & Threshold values & Results & Conclusions \\
\hline WL, RR, IP, SP & F 1 & 4 & $\geq 0.6-0.7$ & 0.795 & supported \\
HCP, CS, OC, VC & F 2 & 4 & $\geq 0.6-0.7$ & 0.748 & supported \\
CSA, CE & F 3 & 2 & $\geq 0.6-0.7$ & 0.633 & supported \\
All attributes & Overall & 10 & $\geq 0.6-0.7$ & 0.842 & supported \\
\hline
\end{tabular}

Table 3 shows the Cronbach alpha test estimates of the 3 latent factors as explained by their respective items (attributes). Factors 1 and 2 have greater than 0.7 internal reliability score while Factor 3 has a score of 0.633 which is considered acceptable. Overall reliability of study attributes was excellent with a score of 0.842 . Hence, the internal reliability of various items in each latent variable was ascertained to be reliable.

Table 4: Relative Importance of Work Attributes Based on CFA Output

\begin{tabular}{llccc}
\hline $\begin{array}{l}\text { Item } \\
\text { Code }\end{array}$ & Work Attributes & $\begin{array}{c}\text { Factor } \\
\text { loadings }\end{array}$ & $\begin{array}{c}\text { Regression } \\
\text { coefficients }\end{array}$ & Ranking \\
\hline WL & Increased workload & 0.822 & 0.664 & 7 \\
RR & Recognition/commendation for sales efforts & 0.784 & 0.774 & 3 \\
1P & Drug Information Provider & 0.624 & 0.730 & 5 \\
SP & Increased sales of your products & 0.554 & 0.693 & 6 \\
HCP & Limited access to doctors, nurses and pharmacists & 0.874 & 0.640 & 8 \\
CS & Limited access to your customers & 0.621 & 0.446 & 10 \\
LC & Observed compliance by people during & 0.501 & 0.734 & 4 \\
& lockdown period & & & \\
VC & Virtual consultation with clients/customers & 0.480 & 0.803 & 2 \\
CSA & Involved in COVID-19 screening activities & 0.754 & 0.538 & 9 \\
CE & Involved in community education & 0.712 & 0.892 & 1 \\
\hline
\end{tabular}

Note: Benchmark was set at factor loadings $\geq 0.45$ 
Table 5 shows the standardized regression coefficients for each of the attribute items in the CFA output. The coefficients revealed the relative importance of each attribute to the study population. The most important item was CE with the highest weight of 0.892 while the least important was CS with a coefficient of 0.446 . The high relevance placed on community education as an extended role of the pharmaceutical sales executive is reflective of the demands caused by the COVID-19 pandemic. Consequently, roles and work structures must be readapted to accommodate this reality in the pharmaceutical sales and marketing industry [Bashir et al., 2021].

Table 5: Test of Construct Validity of Model

\begin{tabular}{llccccc}
\hline Factors & Name & CR & AVE & Factor 1 & Factor 2 & Factor 3 \\
\hline Factor 1 & Sales-related & 0.807 & 0.512 & $\mathbf{0 . 7 1 5}$ & & \\
Factor 2 & Access-related & 0.766 & 0.525 & $0.739 *$ & $\mathbf{0 . 7 2 5}$ & \\
Factor 3 & COVID-19 related & 0.689 & 0.540 & $0.624 *$ & $0.694 *$ & $\mathbf{0 . 7 3 5}$ \\
\hline
\end{tabular}

Note: ${ }^{*} \mathrm{p}<0.001, \mathrm{CR}=$ composite reliability, $\mathrm{AVE}=$ average variance explained

The validity of the structural model was further investigated to determine convergent and divergent validity. Model reliability as measured by CR was supported with values above 0.7 for Factors 1 and 2 as shown in Table 5. However, Factor 3 had an approximate or borderline value of 0.69 and could not be improved on because the latent nature of Factor 3 cannot be improved on by the removal of any item in the structural equation model [Figure 1]. In other words, it would lose its latent nature if only one (1) item is remaining. Convergent validity was measured by having AVE values greater than 0.5, which in this study shows that all factors (latent variables) had AVE values above 0.5. Also, divergent validity was evaluated based on the square root of AVE greater than the intercorrelations of factors along the diagonal [Gaskin \& Lim, 2016; Hu \& Bentler, 1999]. The study showed that divergent validity was confirmed for Factors 2 and 3; however, Factor 2 had concerns as the square root of AVE (0.739) was less than the inter-factor correlation (0.725) along the diagonal [Henseler et al., 2015].

\section{Limitations of the Study}

There are several limitations to the study. Firstly, there is a need to include more items in the study frame in order to improve the extrapolation of the findings. Secondly, there is a need to improve divergent validity concerns by removing items with the lowest loading items (such as 'CS-limited access to customers' in this particular study).

\section{CONCLUSION}

The confirmatory study confirmed the underlying theoretical structure produced by the published exploratory study of work attributes of pharmaceutical executives. The study showed that the most dominant attribute was involvement in community education programs and the least was limited access to customers. Model validity measures were acceptable 
British Journal of Management and Marketing Studies

ISSN: 2689-5072

Volume 4, Issue 4, 2021 (pp. 1-8)

www.abjournals.org

although divergent validity can be improved with more constructs. The study confirmed the validity of the EFA obtained from the previous research work.

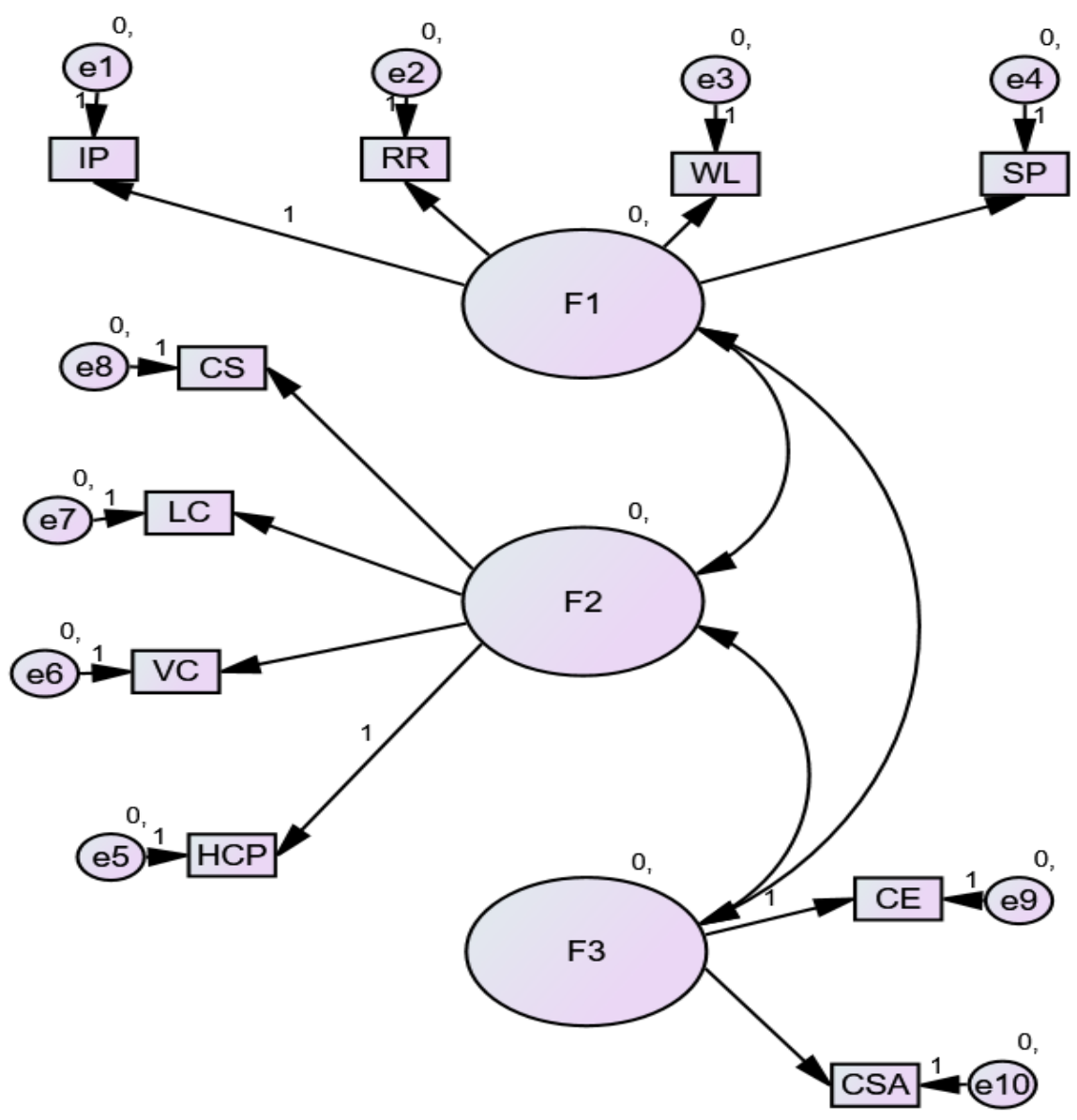

Figure 1: Measurement Model Showing 3 Distinct Factors with a Total of 10 Items

\section{REFERENCES}

Bashir, A., Bashir, S., Rana, K., Lambert, P., \& Vernallis, A. (2021). Post-COVID-19 Adaptations: the shifts towards Online Learning, hybrid course delivery and the implications for Biosciences Courses in the Higher Education setting. Frontiers in Education. 6:711619. Doi. 10.3389/feduc.2021.711619

Cheung, M. W. L. (2009). Statistical Methods- Analyzing Data on Attitudes, Knowledge and Behaviour. Structural Equation Modeling, 1,1-49. 
Elbeddini, A., \& Yeats, A. (2020). Pharmaceutical Intervention amid the coronavirus disease 2019 (COVID-19) pandemic: From direct patient care to telemedicine. Journal of Pharmaceutical Policy and Practice. 13: 1-4. Doi. 10.11.1186/340545-020-00229-z

Fan, Y., Chen, J., Shirkey, G., John, R., Wu, S. R., Park, H., \& Shao, C (2016). Applications of Structural Equation Modeling (SEM) in ecological studies: an updated review. 5:19. Doi. 10.1186/s13717-016-0063-3

Gaskin, J., \& Lim, J., 2016. Master Validity Tool, AMOS Plugin. Gaskination's StatWiki

Goretzko, D., Pham, T. T., \& Buhner, M., (2019). Exploratory factor analysis; Current use, methodological developments, and recommendations for good practice. Current Psychology. 2(2019). https;//doi.org/10.1001.1007/s12144-019-00300-2

Henseler, J., Ringle, C. M., \& Sarstedt, M., 2015. A New Criterion for Assessing Discriminant Validity in Variance-based Structural Equation Modeling. Journal of the Academy of Marketing. 43(1): 115-135

Henson, R. K., \& Roberts, J. K. (2006). Use of exploratory factor analysis in the published literature: Common errors and some comment on improved practice. Educational and Psychological Measurement. 66: 393-416.

Hu, L.T., \& Bentler, P. M. (1999). Cutoff criteria for fit indices in covariance structure analysis: Conventional criteria versus new alternatives. Structural Equation Modeling. 6: $1-55$

Kline, R. B. (2005). Principles and practice of structural equation modeling ( $2^{\text {nd }}$ edition). New York; Guilford

Levine, T.R. (2005). Confirmatory Factor analysis and scale validation in communication research. Communication Research Reports. 22: 335-338

Matsunaga, M. (2010). How to Factor-Analyze your data right: Do's, Don'ts, and How-Tos. International Journal of Psychological Research. 3(1): 97-110

Oamen, T. E (2021a). COVID-19 Pandemic and impact on pharmaceutical sales representatives' operations in West Africa: A socio-demographic case study of Nigeria. African Journal of Social Sciences and Humanities Research. 4(1): 59-72

Oamen, T. E. (2021b). The effects of COVID-19 Pandemic on the Psyche and Productivity of Pharmaceutical Sales Workforce in an African Country: A descriptive case study. 8(5): 586-604. Doi. 10.14738/assrj.85.10161

Oamen, T. E. (2021c). An Exploratory Factor Analysis of Work-Attributes of Pharmaceutical Sales Workforce during COVID-19 Lockdown. Journal of Contemporary Research in Social Sciences. 3(1): 11-27. Doi: 10.33094/26410249.2021.31.11.27.

Schreiber, J. B. (2020). Issues and recommendations for exploratory factor analysis and principal component analysis. Research in Social and Administrative Pharmacy, 15:S1551-7411(20), 30746-30744.Available at: 10.1016/j.sapharm.2020.07.027

Thompson, B. (2004). Exploratory and confirmatory factor analysis. Washington DC: American Psychological Association

Ugbam, O. C., \& Okoro, E. A. (2017). A strategic study of the Nigerian Pharmaceutical sector: Organizational leadership, market share, and competitive performance. International Journal of Business, Humanities, and Technology. 7(1):1-10 


\section{APPENDIX}

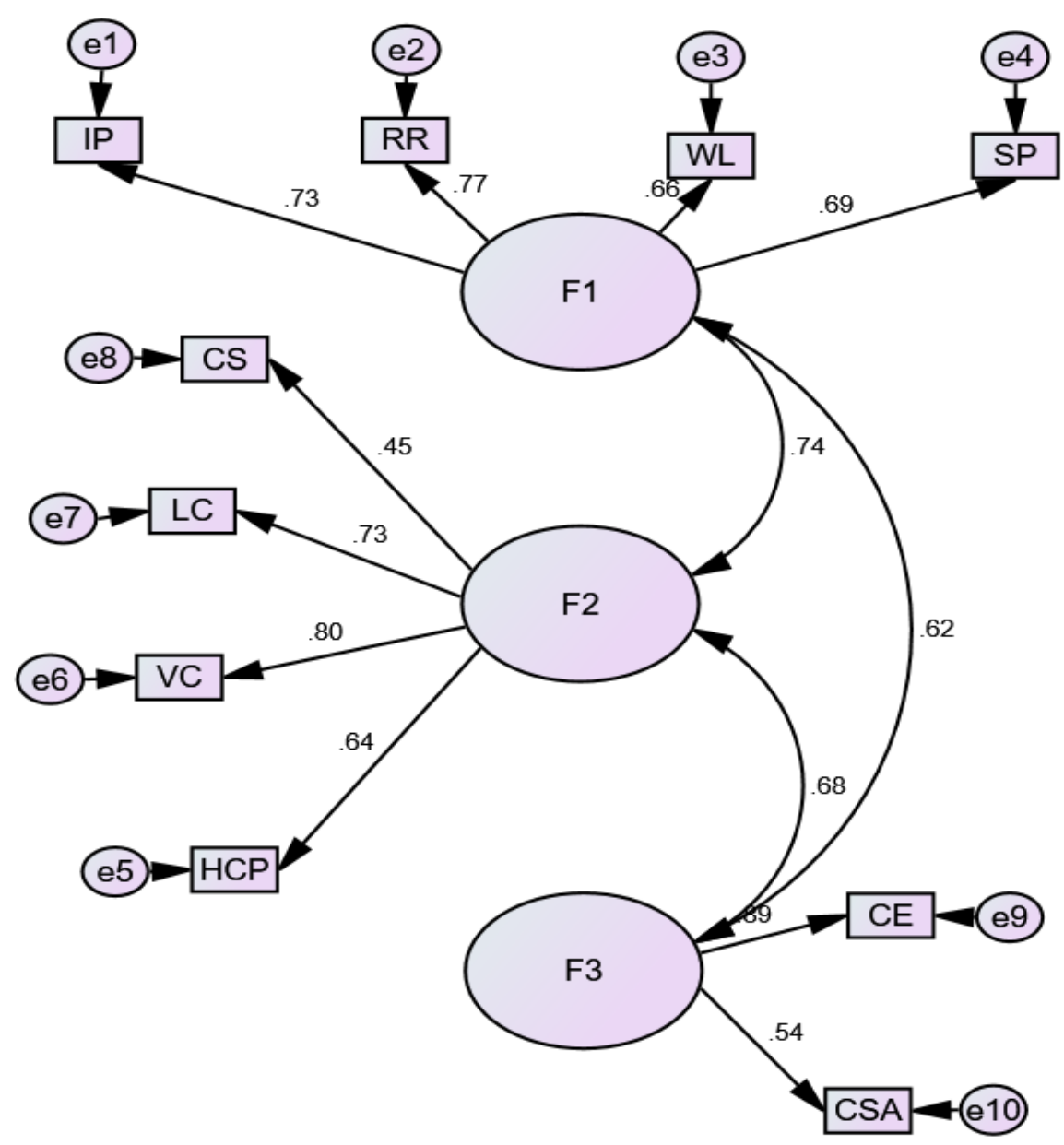

Figure 2. Measurement Model with standardized regression coefficients of study variables 